\title{
Illusion magnitude as a function of visual field exposure
}

\author{
ROBYN K. CLEM and ROBERT H. POLLACK \\ University of Georgia, Athens, Georgia 30602
}

\begin{abstract}
Forty-eight right-handed subjects divided into four groups, each consisting of six males and six females, were employed in an investigation of cerebral hemispheric influence on the perception of tachistoscopically presented simultaneous and successive versions of the Mueller-Lyer figure. The simultaneous version exposed in the left visual field resulted in a larger effect than did right visual field exposures. The successive version exposed in the right visual field resulted in a larger illusion magnitude than it did in the left visual field. The magnitude of visual field differences in response to the successive version was greater than visual field differences found in response to the simultaneous version.
\end{abstract}

Much research in recent years indicates that the cerebral hemispheres are relatively specialized with respect to certain psychological functions. Investigations with subjects who have undergone a cerebral commissurotomy, such as those performed by Gazzaniga, Bogen, and Sperry (1965), Gazzaniga and Sperry (1967), and Levy-Agresti and Sperry (1968) have indicated that the left hemisphere is more proticient in verbal and linguistic skills, while the right hemisphere is superior in analyzing geometric forms and performing tasks involving the visualization of spatial relations. Bogen (1969) found that, following commissure section, geometric designs are copied more accurately with the left hand than with the right hand, although the opposite is true for cursive handwriting. More recent experimental reports (Milner \& Taylor, 1972; Nebes, 1974) have presented compelling evidence of the isolated right hemisphere's superiority in the perception of spatial patterns and spatial and part-whole relations.

Results from cortical lesion studies have also provided evidence of left-hemisphere specialization for verbal and language functions and righthemisphere specialization for spatial, nonverbal operations (Milner, 1971).

Although the directional scanning habits acquired fiom reading complicate the interpretation of some experimental results, systematic laterality effects with respect to visual information have been found in normal subjects. These findings tend to complement the clinical data. Under appropriate viewing conditions. a right visual field (left hemisphere) superiority for the perception and recognition of alphabetical material (Kimura, 1966, 1973) and words (Barton, Goodglass \& Shai, 1965; McKeever \& Huling, $1971 \mathrm{a}$, b) can be demonstrated; as well as a right-field superiority for the perception of familiar objects (Wyke \& Ettlinger, 1961). Efron (1963)

Research was supported by Grant HD 0438-03 from the National Institutes of Health. Requests for reprints should be sent to Robert H. Pollack. University of Georgia, Athens, Georgia 30602. concluded from his experimental results that temporal discrimination of visual stimuli is made by the hemisphere dominant for speech and language, predominantly the left hemisphere. In contrast, a left visual field (right hemisphere) superiority for perceiving the location and quantity of dots (Kimura. 1966; McKeever \& Huling, 1970) and discriminating the slope of lines (Durnford \& Kimura, 1961) has been reported, in addition to a left-tield superiority for face recognition (Rizzolatti, Umilta, \& Berlucchi, 1971). Kimura (1973) and Durnford and Kimura (1971) have shown that the threshold for binocular depth perception is lower in the left visual field than in the right visual tield.

Bogan (1969). Levy-Agresti and Sperry (1968), and Ornstein (1972) are among those researchers who have suggested that the right hemisphere is specialized for Gestalt perception, acting upon information in terms of complex wholes rather than parts, while the left hemisphere is viewed as predominantly analytic, linear, and sequential in its mode of operation. probably due to its mediation of prinary language functions.

Hemispheric specialization research, especially that involving tachistoscopic information processing in normal subjects, has not always revealed consistent findings. White (1971) suggests that this may be due partially to confusion in detining verbal and nonverbal information. For example, it is improbable that certain geometric forms are nonverbal. There is, as well, a possible bias resulting from the traditional use of recognition and recall responses. Also, if the model of differences in hemispheric action proposed by Bogan (1969), Levy-Agresti (1968), and Ornstein (1972) is to be investigated, the experimental tasks used thus far would need to be supplemented. The employment of a geometric illusion, such as the Mueller-Lyer figure, would seem to be useful in reducing, if not eliminating. the above uncertainties. in addition to providing insight into possible functional dissimilarities of the cerebral hemispheres 


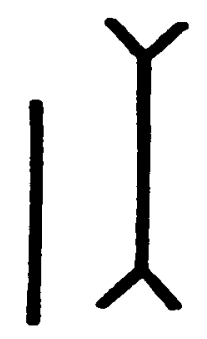

Figure 1. Left visual field exposure of the simultaneous version of the Mueller-Lyer figure.

in the processing of illusory phenomena.

Due to the research of Piaget and his co-workers (Piaget, Lambercier, Boesch, \& Albertini, 1942; Piaget \& Lambercier. 1944). illusions are classified intolwo main groups: Type I phenomena, or primary illusions, which require a simultaneous comparison of the figural parts and show a decrease in illusion magnitude with age; and Type II phenomena, or sccondaty illusions, which require a successive comparison of the figural parts and show an increase in illusion magnitude with age. Pollack (1964) converted the Mueller-Lyer illusion, which is a Type I illusion in its traditional form (Pollack, 1963; Wapner d Werner. 1957). into a Type II phenomenon. This was accomplished by sequentially presenting the parts of the figure's open component (outwardly directed oblique lines), which has been demonstrated to be responsible for about $80 \%$ of the illusory effect (Pollack \& Chaplin, 1964; Pollack \& Zetland, 1965). When presenting this temporally altered version of the illusion to child ren of different ages, the magnitude of the illusion increased with age, reversing the usual trend, in addition to a reversal of the direction of the illusion itself. Pollack (1969) contends that such phenomena (Type II) involve the integration of sequential bits of information over time, with one aspect being a possible "set toward viewing the world as a series of successive events that cohere in an ordered pattern" (p. 26). While Type II phenomena are believed to be related to the developing higher level cognitive processes (Pollack, 1964, 1969), the change in Type $I$ phenomena is not viewed as developmental; instead, the data (Pollack, $1963.1964)$ suggest that it is due to a decline in the sensitivity of the visual receptor as it ages. Pollack (1964) and Spitz and Blackman (1958, 1959) are representative of those researchers who have demonstrated that Type II phenomena appear to be more highly correlated with mental age than with chronological age, while Type I phenomena are more highly correlated with chronological age than with mental age.

The hemispheric specialization data and consequent theorizing cited above suggest that the temporally variant versions of the Mueller-Lyer illusion may be perceived differently when stimulating the different hemispheres. The present study was designed to investigate this suggestion.

\section{METHOD}

\section{Subjects}

The subjects were 24 male and 24 female undergraduate students. ranging in age from 17 to 25 years. All subjects were right -handed and had uncorrected visual acuities of $20 / 20$ or better as measured on a Snellen chart. All subjects were enrolled in an introductory psychology course, but none had had any previous experience with the Mueller-Lyer figure in an experimental setting.

\section{Apparatus and Stimuli}

A three-channel tachistoscope (Scientitic Prototype, Model GB) was employed for stimulus presentation. Illumination in all three channels was kept at a constant 20 apparent foot-candles as measured by a Macbeth illuminometer at the eyepiece.

Two groups of 19 stimuli each were constructed for tachistoscopic use for the simultaneous presentation condition. One group was used for exposure in the left visual field and one for exposure in the right visual field. Each stimulus consisted of the open component (forked ends con nected by a straight line) of the Mueller-Lyer figure and a straight unbounded comparison line. All lines were $1 \mathrm{~mm}$ thick. The angle between the lines of the fork was $90^{\circ}$. The length of the forked lines was $5 \mathrm{~mm}$ and the standard line connecting the two forks was $22 \mathrm{~mm}$. In each case, the top of the comparison line was $5 \mathrm{~mm}$ lower than the top of the standard line. The comparison lines in each group varied in $0.5-\mathrm{mm}$ steps from 20 to $29 \mathrm{~mm}$. For the left-tield group. the forked line was drawn in a vertical orientation and placed $43.3 \mathrm{~mm}$ to the left of a central fixation dot $1 \mathrm{~mm}$ in dian; the straight vertical comparison line was placed $10 \mathrm{~mm}$ to the left of the forked line (see Figure 1). The stimuli for the right-field group were drawn identically, except that the forked line was placed to the right of the central tixation dot and the comparison line was placed to the right of the forked line.

For the successive presentation condition, two stimulus cards with the oblique inducing lines (forked ends) only, as previously described, were constructed, one card being for exposure in the left visual field and one for exposure in the right visual field. Also, two groups of 19 other stimulus cards each were constructed. Each card consisted of the standard and comparison lines, as previously described, drawn appropriately to the left or right of the central tixation dot, with the only difference being that the comparison lines varied in length by $0.5-\mathrm{mm}$ steps from 14 to $23 \mathrm{~mm}$. The standard line of each stimulus card would have connected the respective forked ends had the cards been presented simultaneously (see Figure 2).

Control stimuli for each group consisted of the standard line, without the oblique inducing lines (forked ends), and comparison lines draw $n$ in the same fashion and location as the experimental stimuli. The standard was $22 \mathrm{~mm}$ long and the comparison lines varied in $0.5-\mathrm{mm}$ steps from 20 to $24 \mathrm{~mm}$.

All stimulus tigures were drawn in black India ink on $5 \times 7$ in. white cards. The most central line was $2^{\circ}$ from the central fixation point, while the maximal horizontal visual angle was $2^{\circ} 33^{\prime} 52^{\prime \prime}$. The array subtended a maximum vertical visual angle of $1^{\circ} 39^{\prime} 47^{\prime \prime}$.

\section{Procedure}

The stimulus figures were presented tachistoscopically at a viewing distance of $1,240 \mathrm{~mm}$. In the simultaneous presentation condition, the subjects were divided into two groups, each composed of six males and six females. One group received a left visual field stimulus exposure and one a right-field exposure. Each subject participated in 16 convergent method of limits (Piaget et al.. 1942) series of 19 trials each. The comparison line in each 
series was: $20,29,28.5,20.5,21,28,27.5,21.5,22,27,26.5,22.5$. 23. 26. $25.5,23.5,24,25$, and $24.5 \mathrm{~mm}$. Either a shorter or a longer comparison line was presented as the first stimulus in a series, in the order of abba. The exposure time of each stimulus was $150 \mathrm{msec}$

In the successive presentation condition, the subjects were divided in the same manner for left and right visual tield exposures. Sixteen convergent method of limits series of 19 trials each were run per subject. with the comparison line in each series being: 14, 23, $22.5,14.5,15,22,21.5,15.5,16,21,20.5,16.5,17,20,19.5,17.5$, 18,19 , and $18.5 \mathrm{~mm}$. The same abba order was used to determine whether a shorter or a longer comparison line began each series of trials. In the 16 series. the subject was shown the forked-ends-only card for $150 \mathrm{msec}$. followed by an interval of $500 \mathrm{msec}$, in which a blank field containing only the central fixation dot was shown. followed by a 150 -msec exposure of the standard and comparison lines.

All subjects participated in eight series (four before and four after the experimental trials) of nine control trials. The method of stimulus presentation employed in the experimental conditions was used, with the comparison line in each series being: $20,24,23.5$. $20.5,21,23.22 .5,21.5$. and $22 \mathrm{~mm}$.

The subject's task. in all four groups. was to report whether the comparison line of each stimulus card was shorter or longer than the standard line. "Equal" judgments were not permitted. The subject was instructed to fixate on the central fixation point at all times. Which. when combined with the brief exposure time, prevented possible shifting of the subject's gaze from the fixation dot to the stimulus.

\section{RESULTS}

Points of subjective equality (PSEs), defined as a change in response maintained for three consecutive

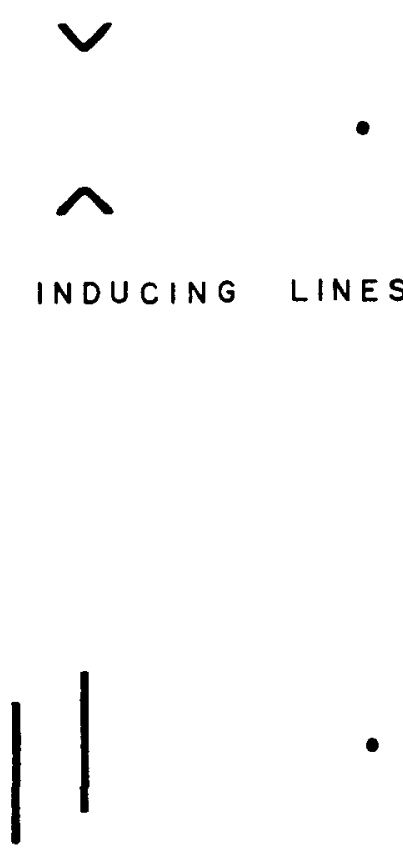

\section{STANDARD AND COMPARISON LINES}

Figure 2. Left visual field exposure of the successive version of the Mueller-Lyer figure.

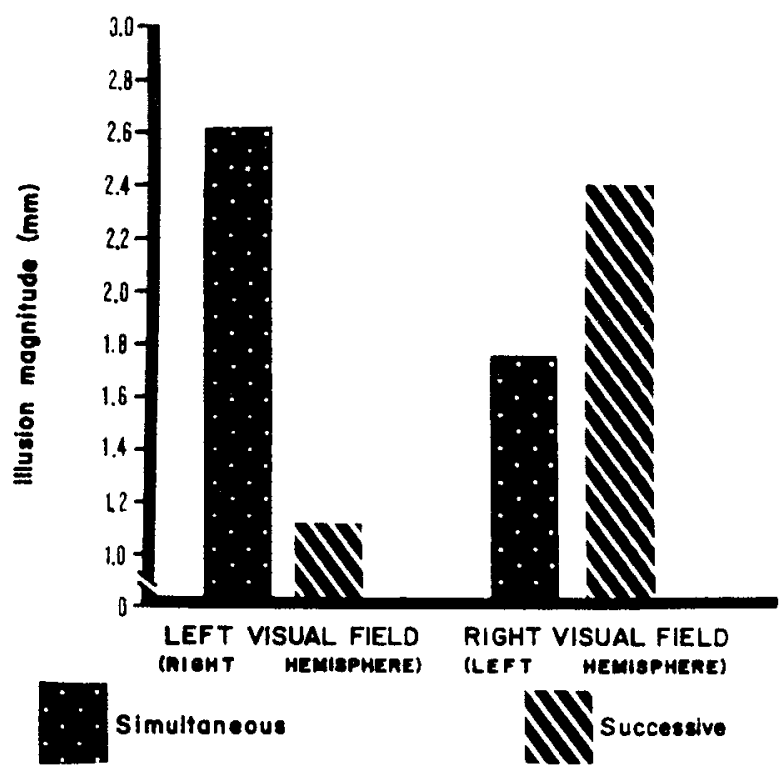

Figure 3. Absolute magnitude of illusion as a function of visual field exposure and temporal order of presentation.

values in ascending or descending order, were determined for each series of trials. The mean PSE across series was then calculated for each subject. In both simultaneous and successive cases, the absolute difference between experimental and control PSEs was taken as the magnitude of the illusory effect. Although the successive Mueller-Lyer is a negative illusion, in that the length of the line between the obliques was underestimated, the data were dealt with only in terms of absolute values of illusion magnitude. Figure 3 illustrates the mean magnitude of illusion, as a function of visual field exposure and temporal order of presentation. for each of the four experimental groups.

Since preliminary data analyses revealed no reliable sex differences. scores from males and females were pooled and the data were analyzed by means of a two-way analysis of variance. No main effect for visual tield (hemisphere) was found, while the temporal order of presentation of the figural components (simultaneous or successive) was significant ( $F=$ 6.47. $\mathrm{d} f=1.44 . \mathrm{p}<.05)$, though this is not of immediate relevance. More importantly, there was a significant Visual Field Exposure by Temporal Order of Presentation interaction $(F=40.23$, df $=1,44$, $\mathrm{p}<.001)$.

A Newman-Keuls test for paired comparisons of the Visual Field by Temporal Order interaction revealed that the left visual field exposure of the simultaneous Mueller-Lyer produced a significantly larger illusion magnitude than did the right visual field exposure of the simultaneous figure. with the exact opposite being true for the successive Mueller-Lyer presentations. In addition. a left-field simultaneous presentation results 
Table 1

Results of Newman-Keuls Test

\begin{tabular}{lcccc}
\hline & $\begin{array}{c}\text { LVF/ } \\
\text { Simul- } \\
\text { taneous }\end{array}$ & $\begin{array}{c}\text { RVF/ } \\
\text { Simul- } \\
\text { taneous }\end{array}$ & $\begin{array}{c}\text { LVF/ } \\
\text { Succes- } \\
\text { sive }\end{array}$ & $\begin{array}{c}\text { RVF/ } \\
\text { Successive }\end{array}$ \\
\hline LVF/Simultaneous & - & $.861^{* *}$ & $1.504^{* *}$ & .221 (n.s.) \\
RVF/Simultaneous & & - & $.643^{*}$ & $.640^{*}$ \\
LVF/Successive & & & - & $1.283^{* *}$ \\
RVF/Successive & & & & - \\
\hline$* p<.05$ & $* * p<.01$ & &
\end{tabular}

in a larger illusion magnitude than a left-field successive presentation, while the reverse occurs for right-field presentations. It was also determined that the smaller simultaneous illusory effect (right visual field) was significantly larger than the smaller successive illusory effect (left visual field). These results are shown in Table 1 . Since a t test revealed no significant difference between left- and right-field responses to control lines $(\mathrm{t}=1.3, \mathrm{df}=46, \mathrm{p}<.50)$, the effect of visual field on judgments of line length per se could be ruled out as a causative factor for the differing illusion magnitudes.

\section{DISCUSSION}

What clearly emerges from these results is that when the figural parts of the Mueller-Lyer illusion are presented simultaneously in the left visual field, projecting to the right cerebral hemisphere, the resulting magnitude of illusion is significantly greater than when the figural parts are presented simultaneously in the right visual field, projecting to the left cerebral hemisphere. Temporally altering the figure into a sequential presentation of its components results in an enhancement of the illusory effect when projected to the left hemisphere, with the illusion magnitude being significantly greater than the seemingly diminished illusory effect produced by projection to the right hemisphere.

These tindings do appear to be in line with the previously cited hemispheric data, as well as supportive of the model of hemispheric operation proposed by Bogen (1969), Levy-Agresti and Sperry (1968, and Ornstein (1972). They suggest that the right hemisphere, with its presumed specialization for Gestalt. holistic perception and its simultaneous mode of processing information, is more susceptible to the traditional simultaneous Mueller-Lyer illusion, while the left hemisphere, with its presumed logical, analytic, sequential mode of processing information, secms to be more susceptible to the successive version of the Mueller-Lyer illusion.

Pollack's (1969) conception that Type II phenomena require temporal integration, the integration over time of traces of past stimulation with ongoing stimulation, combined with the results of this study, suggests that the left hemisphere may be superior in handling this process. It has been proposed that the left hemisphere, in its sequential analysis of input, verbally encodes relevant information for more efticient storage and use (Levy-Agresti \& Sperry, 1968). The possibility exists that modifying the Mueller-Lyer figure into a successive presentation of its parts more readily allows for this association of stimulus details with verbal symbols. The experimental use of a temporal integration task, such as the Hearnshaw (1956) matrix task, might aid in determining whether the hemispheres are actually specialized in regard to temporal integration.

Although this study has not attempted an explanation of the nature of the Mueller-Lyer illusion of illusory effects, the results have importance for the tield of perception and perceptual development research. Piaget (1967) attributes the developmental changes in Type I and Type II phenomena to the same mechanism, the law of relative centrations, which is related to the child's developing ability to look successively at, compare, and integrate perceptual information. Pollack's views concerning the developmental trend of Type II phenomena are complementary to those held by Piaget, though they diverge in respect to Type I phenomena (Pollack, 1969). Pollack (1969) proposes that the age trend of Type I phenomena can be accounted for in terms of the interaction of stimulus factors with the efficiency of the receptor system.

The application of the present experimental design to a study on ontogenetic change might prove to be of assistance in the elucidation of the underlying determinants of the age trends associated with illusory phenomena. The age trend of the simultaneous Mueller-Lyer has proven in the past to be more easily discernible than that of the successive Mueller-Lyer.

The visual field differences demonstrated by the present experimental findings, together with the available information on the developmental changes of Type I and Type II phenomena, imply that the following trends should occur: (1) One would expect simultaneous presentations of the Mueller-Lyer figure to generate illusion magnitudes which decrease with age. It might be expected that the left and right visual field exposures would show similarly shaped functions, with the right-field exposure showing consistently lower illusion magnitudes. (2) Successive presentations of the Mueller-Lyer figure should result in increasing illusion magnitudes with age. One would expect the curves produced by left and right visual field exposure to diverge, with the right field exposure of the successive Mueller-Lyer resulting in a much more pronounced age trend.

A study of this nature might also prove to be useful in understanding the development of hemispheric functional asymmetries. 


\section{REFERENCES}

Bogen, J. E. The other side of the brain, II: An oppositional mind. Bulletin of the Los Angeles Neurological Societies, 1969, 34, 135-162.

Barton, M. I., Goodglass, H., \& Shai, A. Differential recognition of tachistoscopically presented English and Hebrew words in right and left visual tields. Perceptual and Motor Skills, 1965, 21, 431-437.

DURNFORD, M.. \& KIMURA, D. Right-hemisphere specialization for depth perception retlected in visual field differences. Nature, 1971, 231, 394-395.

EFron, R. The effect of handedness on the perception of sinıultaneity and temporal order. Brain, 1963, 86, 261-284.

Gazzaniga, M. S., Bogen, J. E., \& Sperry, R. W. Observations on visual perception after disconnexion of the cerebral hem is pheres. Brain, 1965, 88, 221-236.

Gazzaniga, M. S., \& SPERry, R. W. Language after section of the cerebral commissures. Brain, 1967, 90, 131-148.

HeARnshaw, L. S. Temporal integration and behavior. Bulletin of the British Psychological Society, 1956, 9, 1-20.

KimurA, D. Dual functional asymmetry of the brain in visual perception. Neuropsychologia, 1966, 4, 275-285.

Kimura, D. The asymmetry of the human brain. Scientific American, (March) 1973, 228, 70-78.

Levy-Agresti, J., \& SperRy, R. W. Differential perceptual capacities in major and minor hemispheres. Proceedings of the National Academy of Sciences, 1968, 61, 1151.

McKeever, W. F., \& Huling, M. D. Left cerebral dominance in tachistoscopic word-recognition performances. Perceptual and Motor Skills, 1970, 30, 763-766.

MCKefver, W. F., \& Huling, M. D. Right hemisphere superiority in graphic reproduction of briefly viewed dot figures. Perceptual and Motor Skills, 1971, 31, 201-202. (a)

McKeever, W. F., \& Huling, M. D. Lateral dominance in tachistoscopic word recognition performances obtained with simultaneous bilatera! input. Neuropsychologia, 1971, 9. 15-20. (b)

Milner, B. Interhemispheric differences in the localization of psychological processes in man. British Medical Bulletin, 1971, 27, 272-277.

Milern, B., \& TAYlor, L. Right-hemisphere superiority in tactile pattern-recognition after cerebral commissurotomy: Evidence for nonverbal memory. Neuropsychologia, 1972 , 10. $1-15$.

NebEs, R. D. Hemispheric specialization in commissurotomized man. Psychological Bullotin, 1974, 81, 1-14.

Ornstein, R. The psychology of consciousness. San Francisco: Freeman, 1972.

Piaget, J., lambercier, M., Boesch; E., \& Albertini, B. V.
Recherches sur le développement des perceptions: I. Introduction à l’étude des perceptions chez l'enfant et aNALYSE d'une illusion relative à la perception visuelle de cercles concentriques (Delboeut). Archives de Psychologie Geneve, 1942, 29, 1-107.

Piaget, J.. \& Lambercier, M. Recherches sur le développement des perceptions: V. Essai sur un effet d" Einstellung" survenant au cours de perceptions visuelles, successive (effect Usnadze). Archives de Psychologie, Geneve, 1944, 30, 139-196.

PiageT, J. Problems of genetic psychology. In D. Elkind (Ed.), Sic psychological studies. New York: Random House, 1967. Pp. $116-142$.

Pollack, R. H. Contour detectability thresholds as a function of chronological age. Perceptual and Motor Skills, 1963, 17, 411-417.

Pollack, R. H. Simultaneous and successive presentation of elements of the Mueller-Lyer figure and chronological age. Perceptual and Motor Skills, 1964, 19, 303-310.

Pollack, R. H. Some implications of ontogenetic changes in perception. In D. Elkind and J. Flavell (Eds.), Studies in cognitive development. Oxford: Oxford University Press, 1969.

Pollack, R. H., \& Chaplin, M. Effects of prolonged stimulation by components of the Mueller-Lyer figure upon the magnitude of illusion. Perceptual and Motor Skills, 1964, 18, 377-382.

Pollack, R. H., \& Zetland, F. A translation of "New measurements of visual illusions in children" by Alfred Binet. Perceptual and Motor Skills, 1965, 20, 917-930.

Rizzolatti, G., Umilta, C., \& Berlucchi, G. Opposite superiorities of the right and left cerebral hemispheres in discriminative reaction time to physiognomic and alphabetical material. Brain, 1971, 94, 431-442.

Spitz, H. H.. \& Blackman, L. S. The Mueller-Lyer illusion in retardates and normals. Perceptual and Motor Skills, 1958, 8, 219-225.

Spitz, H. H., \& Blackman, L. S. Studies in mental and retardation: $\mathrm{I}$. A comparison of mental retardates and normals on visual figural aftereffects and reversible figures. Journal of Abnormal and Social Psychology, 1959, 58, 105-110.

WAPNER, S., \& Werner, H. Perceptual development. Worcester, Mass: Clark University Press, 1957.

White, M. J. Hemispheric asymmetries in tachistoscopic information-processing. British Journal of Psychology, 1972, 63. 497-508.

Wyke, M., \& EtTlinger, G. Efficiency of recognition in left and right visual fields. Archives of Neurology, 1961, 5, $659-665$.

(Received for publication August 28, 1974; revision received January 20,1975 .) 